2015-07-29

\title{
Bullying experiences of students with social, emotional and behavioural difficulties (SEBD)
}

Hornby, Garry

http://hdl.handle.net/10026.1/4924

10.1080/00131911.2015.1067880

Educational Review

Informa UK Limited

All content in PEARL is protected by copyright law. Author manuscripts are made available in accordance with publisher policies. Please cite only the published version using the details provided on the item record or document. In the absence of an open licence (e.g. Creative Commons), permissions for further reuse of content should be sought from the publisher or author. 


\section{Educational Review}

\section{Bullying experiences of students with social, emotional and behavioural difficulties (SEBD)}

\section{Eva Brown Hajdukova, Garry Hornby \& Penni Cushman}

To cite this article: Eva Brown Hajdukova, Garry Hornby \& Penni Cushman (2016) Bullying experiences of students with social, emotional and behavioural difficulties (SEBD), Educational Review, 68:2, 207-221, DOI: 10.1080/00131911.2015.1067880

To link to this article: http://dx.doi.org/10.1080/00131911.2015.1067880

\section{Published online: 29 Jul 2015.}

\section{Submit your article to this journal $\square$}

Џ Article views: 205

Q View related articles $\square$

View Crossmark data ¿ 


\title{
Bullying experiences of students with social, emotional and behavioural difficulties (SEBD)
}

\author{
Eva Brown Hajdukova ${ }^{\mathrm{a} *}$, Garry Hornby ${ }^{\mathrm{b}}$ and Penni Cushman ${ }^{\mathrm{b}}$ \\ ${ }^{a}$ Faculty of Education, University of Cambridge, Cambridge, UK; ${ }^{b}$ College of Education, \\ University of Canterbury, Christchurch, New Zealand
}

\begin{abstract}
This article is based on the accounts of 29 boys identified as having severe social, emotional and behavioural difficulties (SEBD) who were attending a residential school in New Zealand. Through in-depth, semi-structured and focus group interviews, a number of salient features of their schooling experiences emerged. One of these features was the experience of bullying. Despite the intuitive connection between SEBD and bullying, little research has directly examined its impact on these students. Results indicated that these students are at increased risk for both victimisation and bullying perpetration and highlight the association between a lack of positive relations with peers and the increased chance of being bullied. The findings also suggested that limitations in teachers' understanding of bullying and their effectiveness in addressing this play a role in its perpetration.
\end{abstract}

Keywords: SEBD; students' experiences; bullying; mainstream schools; residential schools

\section{Introduction}

This article is derived from a study which aimed to explore the schooling experiences of students attending a residential school for children identified as having severe social, emotional and behavioural difficulties (SEBD) in New Zealand. Severe in this case refers to how the nature of the challenging behaviours being presented resulted in these students being placed in the residential school as a last resort. All of them had been excluded from mainstream schools as the schools were unable to cope with the extreme behaviours that arose from their SEBD. The study recognised the inherent value of students' voices because as the recipients of policy-in practice, they possess knowledge and unique insights into the educational system, which are not necessarily recognised by educationists, practitioners or policy-makers. Even though research interest in the elucidation of students' views has expanded considerably over the last few decades, students identified as having SEBD are still underrepresented in this type of research, so further exploration into their voices and perspectives is needed (Sellman 2009). Giving these students a meaningful and influential voice at schools is linked to the development of positive student-teacher relationships, an enhanced sense of belonging to and engagement in school and improved educational outcomes (Cefai and Cooper 2010). The inclusion of these students' perspectives is clearly beneficial for both staff at school and students, yet

*Corresponding author. Email: eva.brownhajdukova@gmail.com 
the value in eliciting students' views as a crucial component of school improvement needs to be acknowledged by practitioners, policy-makers and researchers (McIntyre, Pedder, and Rudduck 2005). This article reports on the material relating to participants' perceptions of their bullying experiences both in the mainstream and residential schools, offers a discussion of the findings and highlights the importance of changing teachers' attitudes towards social and verbal bullying and cultivating positive relationships between peers as a source of protective and remedial factors in the lives of children and youth identified as having SEBD.

\section{Bullying}

Over the past decade, global research into the phenomenon of bullying has expanded considerably as it has become recognised as a pervasive issue present in most schools (Dresler-Hawke and Whitehead 2009). Bullying typically involves aggressive behaviour by peers where the perpetrator persistently and repetitively engages in the harassment of a victim with the intent of gaining a position of power or strength (Monks and Smith 2006). Bullying can be physical or verbal, can involve social exclusion (Farmer, Lane, et al. 2012) and can be perpetrated face-to-face, through peers, or by using electronic means (Ackers 2012).

Three distinct types of bullying involvement have been described (Gumpel 2008). Students identified as bullies repeatedly perpetrate social, emotional, or physical harm against peers but are not themselves bullied by their peers. Those who are the target of peer aggression and are routinely bullied by peers but do not themselves bully peers are identified as victims. Students who perpetrate bullying against peers and are also bullied are considered bully-victims. These three bullying subtypes are associated with distinct types of problem behaviour and social relationships in school (Farmer, Petrin, et al. 2012). When compared to victims and bullyvictims, students identified as bullies tend to have a lower incidence of internalising problems and are more likely to have some socially valued characteristics, even though they are perceived by both teachers and peers as being aggressive and disruptive (Farmer, Lane, et al. 2012). Students identified as victims tend to be socially isolated or have smaller networks when compared to students identified as bullies. Bully-victims tend to have the lowest rate of social acceptance, the fewest positive interpersonal characteristics and use aggressive strategies that are emotionally charged but socially ineffective (Estell et al. 2009). Farmer, McAuliffe Lines, and Hamm (2011) suggests that some students who frequently engage in problem behaviour may be viewed as highly popular, dominant leaders. However, aggressive students who are perceived as unpopular may engage in problem behaviour in order to impress peers, protect themselves against the teasing and taunting of peers, or as engaging in a reactive response to victimisation by peers (Farmer, Petrin, et al. 2012). There is some indication of gender differences relating to bullying behaviour. For example, DeSouza and Ribeiro (2005) argued that boys are more likely to participate in bullying, both as perpetrators and as victims when compared to their female counterparts. Also, a meta-analytic review of gender differences and maladjustment carried out by Card et al. (2008) suggests that although social aggression is invariant for both males and females, males engage in higher levels of direct aggression. 


\section{Teachers' attitudes towards bullying}

An important factor in examining bullying is the teacher's awareness, intervention, and attitudes towards bullies and victims. Research suggests that some teachers might actually tolerate bullying, resulting in an increase in bullying behaviours (Yoneyama and Naito 2003). Teachers have also been found to be inaccurate in estimating the amount of bullying that occurs in their schools, as reflected in discrepancies between the perceptions of students and teachers concerning the prevalence of bullying incidences and its severity (Dedousis-Wallace et al. 2013). Rose, MondaAmaya, and Espelage (2011) argue that teachers may lack knowledge about how to effectively respond when they observe bullying, which has implications for student perceptions of intervention (Espelage, Holt, and Henkel 2003). Dupper and MeyerAdams (2002) pointed out that when students observe a lack of awareness and responsiveness on the part of teachers, they may feel hopeless and believe that effective solutions are impossible. Other research has found that teachers tend to respond more effectively to physical bullying but view verbal or emotional abuse and social exclusion as less severe (Ellis and Shute 2007). Conversely, students rate emotional, verbal, and physical bullying as equally severe (Newman and Murray 2005).

\section{SEBD and bullying}

Students identified as having SEBD are at increased risk of disruptive and antisocial behaviours such as defiance, overactivity, aggression and bullying (Cooper and Cefai 2013). This behaviour represents a challenge to a teacher's daily management, learning and teaching and can destabilise positive classroom climate and safe school environments (Jull 2008). A small but still significant proportion of students identified as having SEBD have mental health problems that often co-mingle with behavioural disorders and learning disabilities (Atkinson and Hornby 2002). Despite the intuitive connection between SEBD and bullying, little research has directly examined these students' experiences with bullying, their engagement and its perpetration and consequences. Current literature that does pertain to SEBD and bullying relates to those subsets of SEBD associated with attention deficit hyperactivity disorder (Taylor et al. 2010), emotional and behavioural disorders (EBD) (Cho, Hendrickson, and Mock 2009; Gumpel and Sutherland 2010) and learning difficulties (Reiter and Lapidot-Lefler 2007). These researchers indicate that students who fall into any of these categories are more likely to be rejected by their peers and are often regarded as unpopular with few friends, making them particularly vulnerable to bullying. Furthermore students with special needs often report social and verbal abuse as the most frequent forms of bullying (Reiter and Lapidot-Lefler 2007). Some research suggests that specifically students identified as having EBD are as likely to be bullies as they are to be victims (Gumpel 2008), and are at a greater risk of displaying bullyvictim behaviours (Gumpel and Sutherland 2010). In a study by Cho, Hendrickson, and Mock (2009), around 60\% of students identified as having EBD were identified as bullies, victims, or bully-victims. Even though it has been empirically validated that students identified as having EBD engage in high levels of reactive aggression (i.e. fighting), reactive emotions (i.e. anger) and proactive aggression (i.e. bullying) (Rose and Espelage 2012), Rose, Monda-Amaya, and Espelage (2011) argue that "the proactive aggression, or bullying may be more accurately defined as reactive aggression or emotion" (p. 135) as it may be a manifestation of the student's disability. 
Published literature related to SEBD suggests that characteristics of students identified as having SEBD are usually associated with attributes that are not desired by peers, which can result in low peer acceptance and increased rates of peer rejection. This may be attributed to the display of behaviours which are externalised and impact on peers (Visser and Dubsky 2009). A study corroborated by Becker and Luthar (2007) also indicated that students who are perceived as too demanding of teacher time, either in terms of behavioural management or "fair share of help" are likely to endure peer rejection. Previous research has identified protective factors that may moderate the relations between the risk factors and the likelihood of children becoming victims and bullies. One such factor that has been highlighted as potentially protective is that of friendship. A study by Flynt and Morton (2004) indicated that supportive peer relationships and classroom participation may buffer against increased levels of victimisation for students with disabilities. According to Bollmer et al. (2005) friends can provide a protective buffer against bullying, however they have to possess certain qualities such as being able and willing "to stick up" for their targeted friend.

\section{Overview of the current study}

A qualitative research design made up of 29 individualised and six focus group interviews was utilised to gain valuable insights into how it is to be a student identified as having SEBD. Through participants' in-depth descriptions this study endeavoured to capture the essence of their schooling experiences in order to gain a better understanding and insight into what it was like to be one of these students in both residential and mainstream schools from each individual's point of view. Phenomenology was utilised as it brought a perspective that matched this aim since phenomenological methods are particularly effective at bringing to the fore the experiences and perceptions of individuals from their own perspectives (Smith, Larkin, and Flowers 2009). Transcendental phenomenology, based on Husserl's descriptive phenomenological philosophy was chosen as the appropriate methodology for this research as the aim was to search for an understanding of the meaning and essence of the participants' schooling experiences thorough their descriptions.

\section{Participants}

The participants in this study were 29 boys, with ages ranging from 9 to 13 years old, all of whom attended a residential school for children identified as having severe SEBD. Girls were not included because the residential school selected for this study only enrolled boys in its programme. All of the participants had been excluded from mainstream schools as they presented behaviours that were seen to be extreme, chronic and beyond the resources of mainstream schools to manage, hence the designation here of severe SEBD. A majority of the participants were diagnosed with mental health problems and disorders. The most common forms of mental health disorders among the participants were anxiety disorders, depression, conduct disorders and attention deficit hyperactivity disorder. Their intellectual ability was within the average range or above. All of the interviewed participants attended the residential school for a minimum of one month to a maximum of one year and 11 months, with an average of six months at the time of the interviews. 


\section{Procedure}

Approval for the study was gained from the University of Canterbury Educational Research Human Ethics Committee, and the Board of Trustees and principal of the residential special school. Approval for their children to be involved was also obtained from all parents and legal guardians. In addition to parental consent, all participants were provided with an opportunity to make their own decisions about participating in this research project. The participation rate was $100 \%$ as all students attending the residential behavioural school at the time of the study expressed their interest and willingness to take part. An introductory session was conducted in order to inform the students what their potential participation would entail. The right to withdraw at any stage of the interviews was emphasised not only in the introductory session, but also before each interview took place.

\section{Interview method and data analysis}

The interview was chosen as a tool of inquiry as it is a suitable way to obtain rich data in phenomenological, qualitative research (Moustakas 1994). Participants were interviewed about their residential experience and also about their experiences in their former mainstream schools. No interview lasted longer than 40 minutes. The questions were concerned with the students' perceptions of their everyday lived experiences in the different educational settings, allowing them the opportunity to voice their own thoughts and opinions about their schooling experiences. The interview methodology was underpinned by the work of Cooper (1993a) who suggests a range of approaches such as congruence, empathy and repeat probing in order to facilitate the interview process. For the individualised interviews a number of broad areas of inquiry were identified and a series of standard open-ended questions were formulated. Such an approach is similar to the "Interview Guide Approach" described by Patton (2002). The implementation of such an approach in this study enabled the process of data collection to be more systematic and comprehensive while the interviews themselves still remained fairly conversational and situational. This enabled the interviewer to remain flexible with the questions while maintaining a relaxed atmosphere that allowed the participants to better engage and express themselves openly. Field notes were written after the interview and used to describe the non-verbal communication and peripheral activity taking place in the setting. All interviews were tape-recorded and transcribed verbatim. In order to validate the data and add credibility to the study a second individual meeting with the same participants was arranged. In this meeting the majority of participants reviewed their own transcripts from which some statements were changed or deleted. Occasionally new statements providing more in-depth and clarifying information were added. In order to gain richer data and add credibility to the study, the decision was made to conduct a series of focus group interviews. Focus group interviews are found to be congruent with phenomenology in three ways. First, focus groups interviews support the notion of collaboration and dialogue instead of privileging the lone researcher and participant (Bradbury-Jones, Sambrook, and Irvine 2009). Second, in traditional phenomenology it is solely the researcher who brackets his or her own prejudices throughout the research process, but in the group discussion both researcher and participant prejudices are challenged by the other group members, thus enabling the researchers to bracket their assumptions (Halling, Kunz, and Rowe 1994). Finally, 
the group approach to phenomenology holds the same benefits as focus groups because it encourages discussion, opens new perspectives, and encourages exchange (Bradbury-Jones, Sambrook, and Irvine 2009). Twenty-four boys (five of the individualised interview participants had finished the residential school programme and returned to their communities) aged between 9 and 13 years participated in the six focus group interviews, which lasted on average one hour. The decisions around group composition were based on the residential school teachers' suggestions as they were more aware of possible disruptive interactions between boys than the researcher and could therefore predict potential dynamics between the participants. The choice of smaller groups was made as groups of three to six members are more suitable for children as they promote lively and manageable discussions (Gibson 2012). The aim of conducting focus group interviews with the same students was two-fold: (1) to further explore and develop the themes described earlier; and (2) to provide another opportunity to capture the students' perspectives and their recommendations on effective pedagogical practice. Despite the expectation in the first aim of adding more in-depth data to the existing themes, only a small portion of new data was obtained as students often repeated and confirmed statements that had already being obtained in the individualised interviews. Nevertheless, this can be viewed as a positive outcome in that it adds to the credibility of the initial findings. The second aim of the focus groups was achieved as students provided their own recommendations for school improvement.

\section{Data analysis}

Phenomenology through its methodology insures the validity of the results by structuring the focus of the research by the identification of the phenomenon of interest and the shared experience (Creswell 2013). In this study the phenomenon of interest was the schooling experiences for 29 students identified as having SEBD who shared not only the condition, but also attended a residential school as a result of being excluded from mainstream school. The method of analysing the data was based on Moustakas's modification of Van Kaam's steps in phenomenological data analysis. While there are many ways of analysing phenomenological data, this approach was selected as it provides systematic steps in the data analysis procedure as well as clear guidelines for assembling the textual and structural descriptions hence assisting in keeping the study rigorous. This approach was also selected as it can limit the researcher's biased conclusions to the analysis of the research data by the implementation of "bracketing" that refers to the need for individuals to temporarily suspend assumptions that are taken for granted and presuppositions about phenomena, which was employed before data analysis started. Following the steps of Moustakas's (1994) phenomenological data analysis, the data was analysed by reducing the information into significant statements related to the phenomenon studied and were highlighted and listed separately. Moustakas (1994) calls this step "horizonalization". These statements were later combined into themes. From these themes the textural description of what the participants experienced and a structural description of how they experienced it in terms of conditions, situations or context were developed, the combination of which conveyed an overall essence of the experience. The thematic units that emerged in this study consisted of many subthemes. The mainstream school experience theme included the following subthemes: relationships with teachers, academic support, relationships with peers, managing 
behaviour, and bullying. The residential school experience theme included the following subthemes: settling down, relationships with teachers, academic support, relationships with peers, managing behaviour, and bullying.

\section{Discussion and results}

This study presents the students' identified as having SEBD perceptions of their personal experience of bullying and its negative consequences. Even though each interviewee had attended a different mainstream school, their insights and perceptions are remarkably consistent, regardless of age and length of stay at the residential school. The findings are reported later under two main headings: Boys' Perceptions of Bullying in Mainstream Schools and Boys' Perceptions of Bullying in the Residential School. The results are presented together with quotations from the students' interviews.

\section{Boys' perceptions of bullying in mainstream schools \\ Being bullied}

None of them [peers] liked me. They never came near me. They called me "fat pig" and "glasses boy" cos I used to wear glasses and they called me a monkey and then they call me Chinese boy. Cos I had a dad that looks like he's from China.

They were laughing at me and saying really mean things to me. Called me psycho. They [the bullies] would not let me in any games. I just sat there alone.

The pain endured by the victims of any type of bullying should not be underestimated. International research has reported a number of negative psychological effects associated with victimisation, such as low self-esteem, sadness and anger (Roland 2002), social adjustment issues manifested in loneliness, isolation and school absenteeism (Rigby 2003), and increased psychological distress, including high levels of anxiety, depression and suicidal thinking (Ayenibiowo and Akinbode 2011). The majority of the boys felt disliked by their mainstream peers and reported being victimised and bullied. Some boys were candid in their analysis of their "unkind" and often aggressive behaviour towards their mainstream peers and acknowledged that it played a crucial role in their difficulties in making and keeping friends. However the majority of the boys did not provide self-reflective accounts and portrayed themselves as victims of peers' dislike and wrongdoing. The boys stressed that they felt socially isolated and rejected, which, in their own words, made them feel "sad", "lonely" and in some cases "angry". Unfortunately, research has found that the perception of being rejected (regardless of whether peer rejection is actually present) can perpetuate both externalising and internalising problems (Deater-Deckard 2001), as the findings in this study also indicate.

The boys' perceptions of why they were bullied included a wide range of external attributes, such as looking different, being physically weak, and overweight or not wearing certain fashionable clothes. These comments support research findings that have concluded that victims are persecuted for external attributes (Hazler 1991; Ma 2001; Swearer and Cary 2003). The most common form of bullying experienced by the boys was verbal bullying, involving behaviour such as teasing and calling names. The next most common form was social bullying which involved behaviours that excluded and isolated the victim. Physical bullying, involving behaviours such 
as kicking, pushing and hitting, was reported by only a few boys. The present findings seem to be consistent with other research which found that social and verbal bullying are the most frequent forms of bullying experienced by students with special needs (Newman and Murray 2005). Unfortunately, these forms of bullying seem to be less noticeable and less likely to be recognised and addressed by teachers (Ellis and Shute 2007). Moreover, as Yoon and Kerber (2003) point out, teachers are more likely to discipline the perpetrators in instances of verbal or physical bullying than they are in the case of social bullying.

\section{Being a bully}

The boys stressed that being a victim of bullying not only negatively impacted their social life and emotional wellbeing but also resulted in negative and often aggressive reactions towards their peers. Interestingly, a great number of boys who were bullied also identified themselves as bullies. However, they felt that their engagement in bullying was a legitimate response to being bullied, often referring to it as selfdefence or fair payback.

They were bullying me, saying really mean things about me and my father. And then I started to learn how to express my anger, hurt others. I would kick, punch, yeah.

They were bullying me, calling me names, hurting me so I started throwing desks and chairs around. Then someone would have to calm me down.

I got bullied most of the time, so that's why I came to this school, because they got payback. They were bullying me, so I bullied them. They were calling me names and yeah. I got very, very angry. I was about to punch somebody.

These findings are in accord with previous studies that suggest that students with elevated rates of both internalised and externalised problems are not only at greater risk of being bullied but are also more likely to engage in bullying (Cho, Hendrickson, and Mock 2009). Some however have argued that the externalised aggression displayed by students identified as having SEBD may be a manifestation of their disability (Rose, Monda-Amaya, and Espelage 2011), an attempt to protect themselves against the teasing and taunting of their peers and, as the findings in this study indicate, a reactive response to victimisation by peers (Farmer, Petrin, et al. 2012). The boys' accounts imply that the coincidence of victimisation, engagement in perpetration, and SEBD may have separate yet compounding effects, substantially heightening students' chances of experiencing even greater psychosocial, behavioural and academic problems, thereby putting them at even greater risk. However, creating opportunities to increase students' social competence and positive interactions may serve to decrease the risk of both bullying and victimisation. Learning how to utilise their strengths, decode social cues, and recognise feelings in themselves and others might well enable students identified as having SEBD to make better choices and interpret situations appropriately (Orpinas and Horne 2006; Pijl, Frostad, and Flem 2008).

\section{Lack of effective intervention in mainstream schools}

If you tell the teacher, at most schools they don't have the time so they don't listen to you. Like they've got more important things to do, so they'll just say, "Oh yeah, we'll 
touch on this later", and they didn't actually really care what you said and in the end they'd forget.

The teachers are likely to forget everything about it [bullying], because they haven't done anything about it.

You get hurt and they never listen. None of the teachers cares.

The majority of boys who identified themselves as victims of bullying in mainstream schools perceived their teachers to be indifferent towards the issue of bullying and ineffective in their handling of bullying incidences. As a result the boys were discouraged from reporting bullying. Similar results were noted in a study by Wise (1999) in which SEBD student interviewees reported inadequate support from their mainstream teachers in preventing incidences and in dealing with bullying. In this study, the boys linked their mainstream teachers' inadequate responsiveness to bullying to their biases against them.

I get angry when people are annoying me. Like just say calling me names, hurting me. Because they know they can get to me. I know that the teachers think that I'm bad, so they'll just go for their side, so I don't bother to say anything.

I know that the school knows that I'm bad, so they'll just go for their side. They won't believe anything I said.

The teachers always blamed things on you, cos you've been in trouble so many times, they think it was you instantly.

If someone hurt me, like kicked me or something, they (the teachers) wouldn't do anything about it. I would overreact and start going off to them and trying to kick them. So they (the teachers) forced me to the ground, not the kids that kicked me.

The teachers say that they were treating me fairly, but I don't reckon they were. I'd do something and the next day, someone else would do the exact same thing as me, but they'd get off lighter than I would. So unfair, they made me so angry.

The teacher was taking the other kids' side when I didn't do anything. I wanted to talk to them, but they wouldn't listen. They never listen. The kids could say the wrong thing to you, hurt you, but the teachers wouldn't do much. It's kind of not the same for everyone else.

The views of students identified as having SEBD regarding teachers' perspectives of these students also appear to be supported in the literature. As previously mentioned (Cooper 1993b; Hamill and Boyd 2002; Pomeroy 1999), teachers may hold a negative attitude towards students whom they perceive as having SEBD and this attitude may lead to the insufficient provision of positive reinforcement and emotional support. These researchers also argue that teachers' biases can exacerbate SEBD, and potentially lead to increased incidences of bullying and victimisation. More importantly, teachers have a strong influence on students' attitudes toward their peers identified as having SEBD (Short and Martin 2005). In their positions as role models, teachers should model appropriate behaviours of caring, sensitivity, and cooperation. Their actions need to reflect support, acceptance, and positive regard while teaching and redirecting behaviours and attitudes that may hinder students' pro-social interactions (Roland and Lawhon 1994). It seems apparent that teachers' attitudes towards these students need to be addressed if bullying prevention programmes producing positive outcomes are to be successfully implemented. There are however, other possible explanations for teachers' limited responsiveness to bullying issues, such as teachers' belief that helping victims of bullying may actually make things worse 
(Duy 2013). Similarly, teachers' failure to intervene could result from a lack of common understanding between the boys' and the teachers' definitions of what bullying is. For example, what one group might define as bullying the other group could interpret as just "rough play". This consideration emphasises the need to increase teacher education regarding the complexity of bullying. Orpinas and Horne (2006) support this claim and stipulate that teachers could benefit from education that extends not only their knowledge of different forms of bullying and its consequences but also deals with effective intervention strategies and the promotion of a positive school climate. The development and maintenance of a positive school culture has been associated with decreased incidences of bullying and improved social and emotional outcomes for all students (Cushman and Clelland 2011).

\section{Boys' perceptions of bullying in the residential school}

There was a consensus among the boys that teachers and staff working at the residential school addressed bullying issues promptly and effectively. Consequently, the residential school was commonly described as a safe place that provided the boys with a respite from bullies.

I'm glad to be away from some of the enemies at the other school. They did not like the person I became a friend with, so they started ganging up, and they started hurting me and then I got a bleeding nose and yeah, so happy to be here.

However, a small number of boys did report being verbally bullied by other boys. Two boys complained that bullies were making insulting and degrading racist comments about them and their families, which resulted in them feeling "sad" and "angry". Even though the victimised boys expressed the desire to retaliate physically, they said they managed to remain calm and not respond as they were fully aware of the strict consequences that would be enforced by teachers and staff for both sides (the bully and the attacker) involved in the incident. Interestingly, no accounts of physical or social bullying were reported. A link between the increased likelihood of bullying and a lack of positive peer relationships was proposed by Taylor et al. (2010). They argued that even though inclusive settings appear to minimise bullying, such settings may actually maintain or exacerbate bullying issues if students with special needs are not fully integrated into their peer group and lack friends or a supportive social network. As friendship has been found to be an important protective factor against bullying (Bollmer et al. 2005), it seems apparent that fostering positive relationships between students with and without disabilities in mainstream schools should be a focus of inclusion. This argument is supported by the boys who expressed their appreciation for the presence of good and supportive friends when dealing with negative interactions with peers.

I had five friends and they really cared. If I got bullied, they'd stand up for me.

I had four friends. They were the ones that kept me going and looked after me when kids were mean to me.

\section{Anti-bullying system}

We write out concern cards. You've got to write your name and you've got to write the problem and where it's happening, and then you give it to the staff member and they read it and then both of us boys get taken to the office and we sort it out. The staff member says what's wrong to both of us and I say my point of view and then 
they say theirs and then we talk about it and then we solve it and we don't bully anymore.

If it happens [bullying], you write out a concern card and they get immediately dealt with. I did have to write one for X, because he was bullying me, calling me names, and even making fun of my family. He doesn't bully me anymore.

The anti-bullying system used by the residential school was also perceived as an effective tool in the fight against bullying. It would appear that the residential school implemented an effective reporting and recording system, which enabled the identification of both vulnerable students and potential bullies, thus resolving issues more effectively. The boys' accounts also suggest that the residential school had clear rules in place about bullying behaviour, a feature that has been associated with lower rates of bullying incidences in Welsh schools (Lambert et al. 2008). Based on the boys' descriptions, the characteristics of the anti-bullying approach used by the teachers seems to be similar to the restorative approach. Here, the underlying principle is to resolve conflict and repair harm by focusing on the perpetrator who is made aware of the victim's feelings, encouraged to acknowledge the impact of what they have done, and given the opportunity to make reparation. Those who have suffered have the opportunity to have their harm or loss acknowledged and amends made (Morrison 2002). Restorative approaches to bullying are highly recommended, since repeated successful outcomes have been reported by the international research community (Morrison, Blood, and Thorsborne 2005; Varnham 2005).

\section{Limitations of the study}

It is important to note that the results presented in this article were acquired from one particular school for a particular subgroup of students, specifically those for whom the residential school environment was deemed appropriate for their education, care and protection. Generalisation of these findings to other groups of students identified as having SEBD would be premature. There are other residential schools in New Zealand for students identified as having SEBD; hence a survey sample of students attending these schools would be required to further explore the generalisability of the present findings. Moreover, it needs to be acknowledged that even though all of the participants were identified as having severe SEBD, there is considerable variability in their social and emotional learning and behaviour, therefore the data presented could be seen as portraying an unwitting homogeneity among the participants. However the aim of the study was to capture the voices of an underrepresented group of students in order to help educationists and practitioners to better understand the complexity of SEBD and thus assist them to better meet their unique needs. Future research could seek the perceptions and experiences of specific sub-groups within SEBD in order to explore how various disorders and difficulties affect students' experiences of bullying.

\section{Implications for practice}

The findings suggest a link between SEBD and victimisation and engaging in bullying. It appears that students identified as having SEBD are at high risk of being bullied and are likely to experience the exacerbation of social, emotional and behavioural problems when they are involved in bullying as victims, perpetrators, or both. It is vital that teachers and school administrators be aware of this link as the 
psychosocial and educational ramifications are significant. Extending teachers' knowledge and understanding of SEBD and how SEBD and bullying interact is crucial. Consequently, for both pre-service and in-service mainstream teachers, there is a need for more education aimed at teaching these students. Addressing bullying issues among students identified as having SEBD more effectively may require teachers to modify their approach to bullying and develop a new repertoire of intervention strategies that are specifically tailored to the unique needs of these students. A change in teachers' attitudes towards verbal and social bullying would also be beneficial. This would entail teachers having a better understanding of the extent and pervasiveness of the specific forms of bullying among these students and how negative consequences can impact and further exacerbate their social, emotional and behavioural problems.

Furthermore, due to social difficulties and poor emotional regulation, students identified as having SEBD are not likely to benefit from the protective factor of supportive peers in mainstream schools. This could be addressed however, by the provision of social skills programmes that enable these students to develop a repertoire of social skills that can strengthen their interpersonal relationships, encourage prosocial behaviour and potentially reduce bullying in schools. Also, successful implementation of school-based peer mentoring programmes might be beneficial. Research has shown that when effectively implemented, these can promote prosocial behaviour among peers and reduce the incidence of bullying, consequently leading to more positive relationships, better attitudes towards school, and improved self-esteem (Randolph and Johnson 2008).

\section{Disclosure statement}

No potential conflict of interest was reported by the authors.

\section{References}

Ackers, M. J. 2012. "Cyberbullying: Through the Eyes of Children and Young People." Educational Psychology in Practice 28 (2): 141-157.

Atkinson, M., and G. Hornby. 2002. Mental Health Handbook for Schools. New York: Routledge/Falmer.

Ayenibiowo, K. O., and G. A. Akinbode. 2011. "Psychopathology of Bullying and Emotional Abuse among School Children.” IFE Psychologia: An International Journal 19 (2): $127-141$.

Becker, B. E., and S. S. Luthar. 2007. "Peer-Perceived Admiration and Social Preference: Contextual Correlates of Positive Peer Regard among Suburban and Urban Adolescents." Journal of Research on Adolescence 17 (1): 117-144.

Bollmer, J. M., R. Milich, M. J. Harris, and M. A. Maras. 2005. "A Friend in Need: The Role of Friendship Quality as a Protective Factor in Peer Victimization and Bullying." Journal of Interpersonal Violence 20 (6): 701-712.

Bradbury-Jones, Caroline, Sally Sambrook, and Fiona Irvine. 2009. "The Phenomenological Focus Group: An Oxymoron?" Journal of Advanced Nursing 65 (3): 663-671.

Card, N. A., B. D. Stucky, G. M. Sawalani, and T. D. Little. 2008. "Direct and Indirect Aggression during Childhood and Adolescence: A Meta-Analytic Review of Gender Differences, Intercorrelations, and Relations to Maladjustment." Child Development 79 (5): 1185-1229.

Cefai, C., and P. Cooper. 2010. "Students without Voices: The Unheard Accounts of Secondary School Students with Social, Emotional and Behaviour Difficulties." European Journal of Special Needs Education 25 (2): 183-198. 
Cho, J., J. M. Hendrickson, and D. R. Mock. 2009. "Bullying Status and Behavior Patterns of Preadolescents and Adolescents with Behavioral Disorders." Education and Treatment of Children 32 (4): 655-671.

Cooper, P. 1993a. Effective Schools for Disaffected Students: Integration and Segregation. New York: Routledge.

Cooper, P. 1993b. "Learning from Pupils' Perspectives." British Journal of Special Education 20 (4): 129-133.

Cooper, P., and C. Cefai. 2013. "Evidence-based Approaches to Social, Emotional and Behavior Difficulties in Schools." KEDI Journal of Educational Policy 10 (3): 81-101.

Creswell, J. W. 2013. Qualitative Inquiry and Research Design: Choosing among Five Approaches. Los Angeles, CA: Sage.

Cushman, P., and T. Clelland. 2011. "A Health Promoting Schools Approach to Bullying." Set: Research Information for Teachers 3 (3): 17-25.

Deater-Deckard, K. 2001. "Annotation: Recent Research Examining the Role of Peer Relationships in the Development of Psychopathol." Journal of Child Psychology and Psychiatry, and Allied Disciplines 42 (5): 565-579.

Dedousis-Wallace, A., R. Shute, M. Varlow, R. Murrihy, and T. Kidman. 2013. "Predictors of Teacher Intervention in Indirect Bullying at School and Outcome of a Professional Development Presentation for Teachers." Educational Psychology 34 (7): 862-875.

DeSouza, E. R., and J. Ribeiro. 2005. "Bullying and Sexual Harassment among Brazilian High School Students." Journal of Interpersonal Violence 20 (9): 1018-1038.

Dresler-Hawke, E., and D. Whitehead. 2009. "The Behavioral Ecological Model as a Framework for School-based Anti-Bullying Health Promotion Interventions." The Journal of School Nursing 25 (3): 195-204.

Dupper, D. R., and N. Meyer-Adams. 2002. "Low-Level Violence a Neglected Aspect of School Culture." Urban Education 37 (3): 350-364.

Duy, B. 2013. "Teachers' Attitudes toward Different Types of Bullying and Victimization in Turkey." Psychology in the Schools 50 (10): 987-1002.

Ellis, A. A., and R. Shute. 2007. "Teacher Responses to Bullying in Relation to Moral Orientation and Seriousness of Bullying." British Journal of Educational Psychology 77 (3): 649-663.

Espelage, D. L., M. K. Holt, and R. R. Henkel. 2003. "Examination of Peer-Group Contextual Effects on Aggression during Early Adolescence." Child Development 74 (1): 205-220.

Estell, D. B., T. W. Farmer, M. J. Irvin, A. Crowther, P. Akos, and D. J. Boudah. 2009. "Students with Exceptionalities and the Peer Group Context of Bullying and Victimization in Late Elementary School." Journal of Child and Family Studies 18 (2): 136-150.

Farmer, T., K. L. Lane, D. L. Lee, J. V. Hamm, and K. Lambert. 2012. "The Social Functions of Antisocial Behavior: Considerations for School Violence Prevention Strategies for Students with Disabilities." Behavioral Disorders 37 (3): 149-162.

Farmer, T., M. McAuliffe Lines, and J. Hamm. 2011. "Revealing the Invisible Hand: The Role of Teachers in Children's Peer Experiences." Journal of Applied Developmental Psychology 32 (5): 247-256.

Farmer, T. W., R. Petrin, D. S. Brooks, J. V. Hamm, K. Lambert, and M. Gravelle. 2012. "Bullying Involvement and the School Adjustment of Rural Students with and without Disabilities." Journal of Emotional and Behavioral Disorders 20 (1): 19-37.

Flynt, S. W., and R. Collins Morton. 2004. "Bullying and Children with Disabilities." Journal of Instructional Psychology 31 (4): 330-333.

Gibson, J. E. 2012. "Interviews and Focus Groups with Children: Methods That Match Children's Developing Competencies." Journal of Family Theory and Review 4 (2): 148-159.

Gumpel, T. P. 2008. "Behavioral Disorders in the School: Participant Roles and Sub-Roles in Three Types of School Violence." Journal of Emotional and Behavioral Disorders 16 (3): 145-162.

Gumpel, T. P., and K. S. Sutherland. 2010. "The Relation between Emotional and Behavioral Disorders and School-Based Violence." Aggression and Violent Behavior 15 (5): 349-356.

Halling, S., G. Kunz, and J. O. Rowe. 1994. "The Contributions of Dialogal Psychology to Phenomenological Research.” Journal of Humanistic Psychology 34 (1): 109-131. 
Hamill, P., and B. Boyd. 2002. "Equality, Fairness and Rights-The Young Person's Voice." British Journal of Special Education 29 (3): 111-117.

Hazler, R. J. 1991. "Student Perceptions of Victimization by Bullies in School." Journal of Humanistic Education and Development 29 (4): 143-150.

Jull, S. K. 2008. "Emotional and Behavioural Difficulties (EBD): The Special Educational Need Justifying Exclusion.” Journal of Research in Special Educational Needs 8 (1): 13-18.

Lambert, P., J. Scourfield, N. Smalley, and R. Jones. 2008. "The Social Context of School Bullying: Evidence from a Survey of Children in South Wales." Research Papers in Education 23 (3): 269-291.

Ma, X. 2001. "Bullying and Being Bullied: To What Extent Are Bullies Also Victims?" American Educational Research Journal 38 (2): 351-370.

McIntyre, D., D. Pedder, and J. Rudduck. 2005. "Pupil Voice: Comfortable and Uncomfortable Learnings for Teachers." Research Papers in Education 20 (2): 149-168.

Monks, C. P., and P. K. Smith. 2006. "Definitions of Bullying: Age Differences in Understanding of the Term, and the Role of Experience." British Journal of Developmental Psychology 24 (4): 801-821.

Morrison, B. 2002. Bullying and Victimisation in Schools: A Restorative Justice Approach. Woden: Australian Institute of Criminology.

Morrison, B., P. Blood, and M. Thorsborne. 2005. "Practicing Restorative Justice in School Communities: Addressing the Challenge of Culture Change." Public Organization Review 5 (4): 335-357.

Moustakas, C. E. 1994. Phenomenological Research Methods.Thousand Oaks, CA: Sage.

Newman, R. S., and B. J. Murray. 2005. "How Students and Teachers View the Seriousness of Peer Harassment: When is It Appropriate to Seek Help?" Journal of Educational Psychology 97 (3): 347-365.

Orpinas, P., and A. M. Horne. 2006. Bullying Prevention: Creating a Positive School Climate and Developing Social Competence. Washington: American Psychological Association.

Patton, M. Q. 2002. Qualitative Research and Evaluation Methods. Thousand Oaks, CA: Sage Publications.

Pijl, S. J., P. Frostad, and A. Flem. 2008. "The Social Position of Pupils with Special Needs in Regular Schools.” Scandinavian Journal of Educational Research 52 (4): 387-405.

Pomeroy, E. 1999. "The Teacher-Student Relationship in Secondary School: Insights from Excluded Students." British Journal of Sociology of Education 20 (4): 465-482.

Randolph, K. A., and J. L. Johnson. 2008. "School-based Mentoring Programs: A Review of the Research." Children and Schools 30 (3): 177-185.

Reiter, S., and N. Lapidot-Lefler. 2007. "Bullying among Special Education Students with Intellectual Disabilities: Differences in Social Adjustment and Social Skills." Intellectual and Developmental Disabilities 45 (3): 174-181.

Rigby, K. 2003. "Consequences of Bullying in Schools." Canadian Journal of Psychiatry 48 (9): 583-590.

Roland, E. 2002. "Bullying, Depressive Symptoms and Suicidal Thoughts." Educational Research 44 (1): 55-67.

Roland, S. D., and T. Lawhon. 1994. "How Do I Love Thee: Enhancing Intimacy in Children." Childhood Education 71 (1): 38-41.

Rose, C. A., and L. E. Espelage. 2012. "Risk and Protective Factors Associated with the Bullying Involvement of Students with Emotional and Behavioral Disorders." Behavioral Disorders. 37 (3): 133-148.

Rose, C. A., L. E. Monda-Amaya, and D. L. Espelage. 2011. "Bullying Perpetration and Victimization in Special Education: A Review of the Literature." Remedial and Special Education 32 (2): 114-130.

Sellman, E. 2009. "Lessons Learned: Student Voice at a School for Pupils Experiencing Social, Emotional and Behavioural Difficulties." Emotional and Behavioural Difficulties 14 (1): 33-48.

Short, C., and B. N. Martin. 2005. "Case Sudy: Attitudes of Rural High School Students and Teachers regarding Inclusion." Rural Educator 27 (1): 1-10.

Smith, J. A., M. Larkin, and P. Flowers. 2009. Interpretative Phenomenological Analysis: Theory, Method and Research. London: Sage. 
Swearer, S. M., and P. T. Cary. 2003. "Perceptions and Attitudes toward Bullying in Middle School Youth: A Developmental Examination across the Bully/Victim Continuum." Journal of Applied School Psychology 19 (2): 63-79.

Taylor, L. A., C. Saylor, K. Twyman, and M. Macias. 2010. "Adding Insult to Injury: Bullying Experiences of Youth with Attention Deficit Hyperactivity Disorder." Children's Health Care 39 (1): 59-72.

Varnham, S. 2005. "Seeing Things Differently: Restorative Justice and School Discipline." Education and the Law 17 (3): 87-104.

Visser, J., and R. Dubsky. 2009. "Peer Attitudes to SEBD in a Secondary Mainstream School." Emotional and Behavioural Difficulties 14 (4): 315-324.

Wise, S. 1999. "Improving Success in the Mainstream Setting for Pupils with Emotional and Behavioural Difficulties." Pastoral Care in Education 17 (3): 14-20.

Yoneyama, Shoko, and Asao Naito. 2003. "Problems with the Paradigm: The School as a Factor in Understanding Bullying (with Special Reference to Japan)." British Journal of Sociology of Education 24 (3): 315-330.

Yoon, Jina S., and Karen Kerber. 2003. "Bullying: Elementary Teachers' Attitudes and Intervention Strategies." Research in Education 69 (1): 27-35. 